\title{
AN EMPIRICAL INVESTIGATION OF THE PURCHASING POWER PARITY HYPOTHESIS IN EUROPEAN TRANSITION COUNTRIES
}

\author{
Václav Žd'árek*
}

\begin{abstract}
:
The article is aimed at empirical investigation of the relative version of the purchasing power parity (PPP). It attempts to shed some light on the so-called 'PPP puzzle' for selected countries in the CEE region and Turkey. Because of ambiguous results in the literature, various econometrics methods are employed: univariate tests (URTs: ADF, PP, KPSS, DF-GLS), robust URTs including nonlinear URTs (Kapetanios and Sollis' and Bierens' test) and tests allowing for (multiple) structural breaks (Perron, Lee and Strazicich). The euro currency pairs (bilateral) of 10 European transition countries covering the period 1995:1-2011:1 are utilized. Our results for conventional linear (such as ADF or PP test) do not provide a crystal-clear answer, more robust URTs at least partially do, once the source of nonlinearities has been controlled for (structural changes, non-zero adjustment costs). Nonlinear tests with structural breaks provide more convincing evidence in favour of the PPP hypothesis including asymmetrical effects of exchange rate adjustments.
\end{abstract}

Keywords: real exchange rates, unit root, exponential smooth transition autoregressive model, transition countries

JEL Classification: E51, F21

* Václav Žd'árek, University of Economics, Department of Monetary Theory and Policy, W. Churchill Sq. 3, 13067 Prague 3 (zdarekv@vse.cz). I am grateful to K. Staehr, B. Vašíček, one anonymous PEP referee and participants of the 8th biannual conference of the Czech Economic Society and XII Conference on International Economics in Castellón de Plana for their comments, suggestions and stimulating discussions.

A part of this paper was written with the support of a grant provided by the Ministry of Education, Youth and Sports (Centre for Research of the Czech Economy's Competitiveness 1M0524). The usual disclaimers apply.

This paper has won the $2^{\text {nd }}$ prize in the PAPER'11 contest announced by the Czech University of Economics in Prague. 


\section{Introduction}

Real exchange rates and the purchasing power parity (PPP) in particular belong to the well-known six main puzzles in macroeconomics mentioned in a seminal paper written by Rogoff (1996). A large number of studies have been aimed at examining the PPP hypothesis, both in developed and to a lesser extent in developing countries. Empirical results seem to have been mainly in favour of supporting PPP in developed countries; for example recent articles focused on selected OECD countries (e.g. Chortareas and Kapetanios (2009) or EU15 countries (e.g. Christidou and Panagiotidis (2010). However, findings have been mixed for developing and transition countries, depending on the set of countries, time period, price indices, and applied econometric techniques. Some studies have even rejected the PPP hypothesis while using (robust) univariate unit root tests (hereinafter referred to as $U R T S$ ) and more recently panel unit root tests. While the former are exposed to criticism due to low power, the latter have solved some problems of URTS but simultaneously created new ones (owning to no adjustments for structural breaks, problems with cross-correlation, symmetrical adjustments, etc., see e.g. Bahmani-Oskooee et al., 2008).

Transition countries in Europe have not been paid much attention so far. This might have been for a number of reasons: firstly, the availability of data has been limited and the radical and deep structural changes during the 1990s make any analysis difficult, ${ }^{1}$ secondly, some countries did not exist before $1993,{ }^{2}$ which puts limits on available time series. Several studies have tried to overcome this problem by using data for the black market. However, given characteristics of the former regimes in most of the new EU member states (NMS), ${ }^{3}$ it is not certain how valid these data and their results are.

Some authors cast doubts on the PPP theory and its empirical testing, since PPP is a (very) long-run concept of exchange rate determination (in the horizon of decades for instance), which may span different exchange rate regimes and monetary policy environments (see e.g. Alba and Papell, 2007). However, there are many reasons for looking at PPP that are rather of a more general character: PPP is one of the necessary assumption for exchange rate modelling (e.g. for monetary models from the 1970s), a starting point for many models in international finance or it is assumed to be satisfied in many macro models, which may be true in the long run, but not necessarily in the short and/or medium run.

To date there has been no empirical study that would use both approaches and a large set of CEE countries to our best knowledge. The main contributions of this study can be summarised as follows: PPP is tested vis-à-vis the euro currency ${ }^{4}$ and both

1 The same does hold true for developing (transition) countries in general, for an overview see e.g. Bahmani-Oskooee et al. (2008).

2 The Czech Republic and Slovakia or 1990 in the case of the Baltic States.

3 NMS as synonyms for all the countries from the 5th and 6th waves of EU enlargement (2004 and 2007).

4 Standard approach is to test PPP against the US dollar or a 'synthetic currency' (real effective exchange rate, REER), see e.g. Bahmani-Oskooee et al. (2008) or Telatar and Hasanov (2009). 
conventional URTs and high power URTs compared to conventional ADF (the ESTAR models and the Bierens (1997) tests), while focusing on quarterly instead of monthly data for CEE countries that have not adopted the euro (Bulgaria, Croatia, the Czech Republic, Hungary, Latvia, Lithuania, Macedonia, Poland, and Romania) and Turkey. Two approaches - univariate URTS and a battery of tests robust to various violations of standard assumptions (such as structural breaks) - allow us to employ various robust techniques allowing for different potential sources of influences, factors that may influence results. ${ }^{5}$

The paper is structured as follows. The second section aims at summarizing the literature and explaining our empirical strategy and it also describes the tests employed. The next section briefly overviews the construction of the dataset. The third section presents and discusses the results of our empirical analysis in the light of various robustness tests and it also overviews some pitfalls for empirical analysis. The last section concludes and offers possible extensions of this study.

\section{Theoretical Foundations}

There are two versions of the PPP - an absolute or a relative version. ${ }^{6}$ The PPP is based on several theoretical assumptions that must be satisfied (see MacDonald, 2007). The absolute PPP is a generalization of the 'law of one price' (LOP). A log-linearised form of the relative version of the PPP (hereinafter referred to as simple PPP unless indicated otherwise) can be written as: ${ }^{7}$

$$
q_{t}^{i, r c}=e_{t}^{i, r c}-p_{t}^{i}+p_{t}^{r c}
$$

where $e_{t}^{i, r c}$ the is the log of the nominal exchange rate (the direct quotation of the exchange rate, i.e. the a-country--domestic-currency price of foreign currency (the euro), $p_{t}^{i}$ and $p_{t}^{r c}$ are the logs of domestic and foreign price levels $(i$ is the $i-t h$ country, $r c$ is the foreign country price level - the euro area level) and $t$ is the time. A generalization of the model in the equation (1) (the 'strong' PPP hypothesis) is the 'weak' PPP hypothesis, whose model takes the form:

$$
q_{t}^{i, r c}=-p_{t}^{i}+\beta_{0} p_{t}^{r c}+\beta_{1} e_{t}^{i, r c}
$$

where the variables are the same as in the previous model, is used for distinguishing both approaches and the coefficients $\beta_{0}$ and $\beta_{1}$ reflect the existence of measurement and transaction costs (such as transport costs). Throughout the text the model (1) is used

5 A set of robustness checks were done for the US dollar and REER and shorter time spans. These results are available upon request.

6 Sometimes these forms are referred to as to the 'weak' and 'strong' version of the PPP hypothesis, see Taylor and Taylor (2004).

7 Some studies have used one of the approaches, e.g. Juvenal and Taylor (2008) takes only the US economy as the benchmark country or the real exchange rate $\left(q_{t}\right)$ is split into two components, one being traded-goods, the other non-traded goods, see Maican and Sweeney (2006). 
following the literature. Nevertheless, transaction costs are allowed for indirectly and therefore, the so called ESTAR models are employed in the empirical part of this paper.

\subsection{A brief review of literature}

Empirical evidence on the PPP hypothesis in transition and developing countries has been mixed. There have been several studies that focused both on individual countries (for example an early study by Thacker (1995), rejecting PPP both for Poland and Hungary) and on groups of countries. While studies that have used conventional URTs have not found support for PPP (e.g. Cuestas, 2009; Acaravci and Ozturk, 2010), studies employing non-linear models (ESTAR models) have shown mixed results depending on the covered time period, frequency of data, group of countries, and currency pairs (mainly USD and REER, recently euro pairs), for example Telatar and Hasanov (2009), a study covering $25 \mathrm{CEE}$ countries by Bahmani-Oskooee et al. (2008), for four bilateral PPPs (CPI based) Bekö and Boršiè (2007).

There have also been attempts to apply other time series methods (cointegration: Johansen for individual countries and Larson's for a panel) by Sideris (2006) who finds support for both weak and strong versions of PPP, Koukouritakis (2009) finds that PPP holds for four out of twelve NMS countries.

An increasing number of studies, however, have utilised URTs allowing for structural breaks for structural shifts and outliers (simple ADF and modified tests based the 'first' generation URTs such as Perron (1997 or the 'second' generation e.g. Lee and Strazicich, 2003, 2004) and this approach has found significant evidence in the favour of PPP (i.e. a non-rejection of the PPP hypothesis), for example Acaravci and Ozturk (2010), Maican and Sweeney (2006).

\subsection{Estimation strategy}

The relative version of the PPP hypothesis can be tested by verifying properties of $q_{t}$ (the equation (2)), i.e. testing the $q_{t}$ (real exchange rate) for a unit root. If $q_{t}$ followed a non-stationary process (e.g. I(1), i.e. random walk), then the PPP would not hold in the long run due to non-stationary properties. ${ }^{8}$ On the other hand, if a unit root is not present in a time series, it means that a deviation from equilibrium is only of a temporary nature and the PPP does hold in the long run (for a modified interpretation see below).

If the relative version of PPP is tested, it is verified that exchange rate oscillates within 'a certain band', i.e. around $1(1 \pm \Delta$ with $\Delta$ being a deviation, theoreticaly $\Delta \rightarrow 0)$ which is the long-run level of an exchange rate in an economy if strict assumptions of the PPP theory are satisfied. A simple test of the PPP hypothesis makes use of the following equation:

8 A shock influencing this time series would lead to disequilibrium that would not be restored due to increasing variance and non-existence of unconditional mean of this time series, see Fan and Yao (2003). 


$$
\Delta q_{t}=\alpha+\rho q_{t-1}+v_{t}
$$

where $q_{t}$ is the time series (i.e. a real exchange rate) defined in the equation (2), $\rho \in(0,1)$ is an autoregressive parameter and $v_{t}$ is the error term (a sequence of normal variables, $i i d$, with zero mean and variance $\sigma_{v}^{2}$ ). Under the null (non-stationarity) $\rho=0$ and for $\alpha \neq 0$ the real exchange rate $q_{t}$ follows a random walk with drift (or with a time trend determined by the value of $\alpha$ ). Under the alternative, mean reversion occurs since $\rho \in(-1,0)$ with $-\rho$ determining the speed of adjustment towards equilibrium. In order to observe PPP, a time series $\left(q_{t}\right)$ has to be stationary and it is not driven by any permanent shocks (see Maican and Sweeney, 2006).

\subsection{Univariate unit root tests}

We begin with univariate linear (the Augmented Dickey-Fuller test (ADF), the PhillipsPerron test (PP) and the Kwiatkowski-Phillips-Schmidt-Shin tests, KPSS), in the next turn, non-linear URTS such as the DF-GLS test that is a modified Dickey-Fuller test transformed by a GLS regression; for details see Harris and Sollis (2005) and finally, modified versions of URTs adjusted to the case of structural breaks are applied to data. Univariate linear URTs assume the existence of unit root under the null, the alternative means mean reversion (the PPP hypothesis holds, see above). The only exception in our set of univariate linear tests is the KPSS test, whose hypotheses are inverted. One reason for employing this test is guided by the fact that it has been shown to be more difficult to reject the null of non-stationarity in the case of transition countries.

Since in real financial markets cannot be expected that observed PPP deviations will be corrected by a linear adjustment process, non-linear tests are applied as well. Such deviations can be observed due to the existence of transaction costs. Only if these deviations are large enough to cover the costs, they are corrected by market forces. However, if an adjustment followed a non-linear path, standard URTS would be biased and URTS would lead to higher likelihood of accepting the alternative hypothesis of stationarity. This has lead researchers to employ exponential models allowing for costs of arbitrage, i.e. they enable us to model bands of 'inactivity' and various speeds of adjustment to equilibrium. ${ }^{9}$

\subsection{ESTAR model}

One approach that allows for the costs of arbitrage (transaction costs) is a test proposed by Kapetanios et al. (2003) which is an extension of the ADF test and it uses an ESTAR specification (an exponential transition function, $d=1$ is assumed) as (KSS test thereafter):

$$
\Delta x_{t}=\rho x_{t-1}\left[1-\exp \left(-\zeta x_{t-1}^{2}\right)\right]+v_{t}, \quad \zeta \geq 0,
$$

9 Another possibility is to use threshold models, which distinguish between bands with adjustments to equilibrium and without it. 
where $x_{t}$ is the time series (e.g. one exchange rate) in the form of a demeaned or a detrended time series, $\left[1-\exp \left(-\zeta x_{t-1}^{2}\right)\right]$ is the exponential transition function. If $\zeta>0$, it affects the speed of mean reversion and $v_{t}$ is the error term (i.i.d., $\left.v\left[\mu_{v}, \sigma_{v}^{2}\right]=v\left[0, \sigma_{v}^{2}\right]\right)$.

The null hypothesis is $H_{0}: \zeta=0\left(\Delta x_{t}=v_{t}\right)$, which means that the term in brackets ([.]) is zero, i.e. $x_{t}$ is non-stationary. The alternative is $H_{0}: \zeta=0$. In this case the parameter drives the speed of a mean reverting process. However $\zeta$ in the model (4) cannot be used to test the $H_{0}$ directly since the parameter $\rho$ is not identified. A solution is based on a Taylor series approximation:

$$
\Delta x_{t}=\psi x_{t-1}^{3}+\varepsilon_{t},
$$

where $\psi=\rho \zeta$ and $\varepsilon_{t}=\xi_{t}+\Theta_{t}$ is the new error term (i.i.d.), with $\Theta_{t}$ being the reminder term from the 1 st order Taylor expansion.

A generalisation of the model (5) deals with high-order dynamics and helps to solve problems with serial correlation of the error term $\varepsilon_{t}$ :

$$
\Delta x_{t}=\psi x_{t-1}^{3}+\sum_{i=1}^{k} \omega_{i} \Delta x_{t-i}+\varepsilon_{t}^{\prime}
$$

where the sum augments the model (6) with $k$ lags of $\Delta x_{t}$, so that the i.i.d. error term $\varepsilon_{t}^{\prime}$ is not serially correlated.

The $H_{0}$ in the models (5) and (6) remains unchanged, the alternative is $H_{1}: \psi<0$. Kapetanios et al. (2003) use Monte Carlo simulations to show that the test statistics $\left(t_{N L .}\right)^{10}$ in both equations (5) and (6) have good finite-sample properties. Since the $t$-statistics $\left(t_{N L .}\right)$ are not standard normally distributed, the critical values must be tabulated via simulations. If the $H_{0}$ is rejected, it means that time series reverses to a constant mean (demeaned data), i.e. it supports PPP. ${ }^{11}$ Although linear or nonlinear reversion of a time series to a trend (detrended data) would sensu stricto mean a support for the B-S effect.

\subsection{Asymmetries in adjustments - AESTAR model}

Some authors argue that there may be asymmetries regarding adjustments of exchange rates after a depreciation/appreciation. An extension of the ESTAR model - briefly summarised in the section 1.4 - that allows for asymmetries is suggested by Sollis (2009). Since it is a combination of an exponential and a logistic function, it is dubbed as an asymmetrical ESTAR model (AESTAR). The AESTAR model can be written for a transition variable, exchange rate $x_{t}$ :

10 '..' in the expression is left out for individual variants of the KSS test. The test statistics is $t_{N L . .}=\frac{\hat{\delta}}{s e(\hat{\delta})}, \hat{\delta}$ is the least squares estimate of $\delta, \hat{\delta}$ is the standard error.

11 A reversal to a mean $(=0)$ is also one possibility, however, it is not a possibility in the exchange rate context. 
$\Delta x_{t} \quad$ üüü̈̈̈ $\quad-\zeta_{1} x_{t-1}^{2}$

$$
\left\{\left[1+\exp \left(-\zeta_{2} x_{t-1}\right)\right]^{-1} \rho_{1}+\left(1-\left[1+\exp \left(-\zeta_{2} x_{t-1}\right)\right]^{-1}\right) \rho_{2}\right\} x_{t-1}+v_{t},
$$

$$
\zeta_{1}, \zeta_{2} \geq 0
$$

where $v_{t}$ the error term is assumed to be an i.i.d. sequence, $v_{t} \in\left[0, \sigma_{v}^{2}\right]$.

If $\zeta_{2} \rightarrow 0$ is assumed, then $T_{t}\left(\zeta_{2}, x_{t-1}\right) \rightarrow 0.5 \forall_{t}$. It implies that any values $\rho_{1}, \rho_{2}$, do not affect symmetrical behaviour of the adjustment process. The parameter $\xi_{2}$ controls the degree of asymmetry. The assumption $\rho_{1} \neq \rho_{2}$ means different (autoregressive) adjustment processes on either side of an attractor (a zero mean, a non-zero mean or a deterministic trend).

The $H_{0}$ (unit root) can be tested against the alternative of a globally stationary symmetric or asymmetric ESTAR nonlinearity via $H_{0}: \zeta_{1}=0$. However, the remaining parameters cannot be identified under the $H_{0}$. An approximation is used instead (Sollis, 2009 shows all steps):

$$
\Delta x_{t}=\psi_{1} x_{t-1}^{3}+\psi_{2} x_{t-1}^{4}+\varepsilon_{t}
$$

or an augmented model with additional $k$ terms $\left(\Delta x_{t}\right)$ allowing for higher-order dynamics:

$$
\Delta x_{t}=\psi_{1} x_{t-1}^{3}+\psi_{2} x_{t-1}^{4}+\sum_{i=1}^{k} w_{i} \Delta x_{t-i}+\varepsilon_{t}^{\prime}
$$

where the sum augments the model (8) with $k$ lags of $\Delta x_{t}$, so that the i.i.d. error term $\varepsilon_{t}^{\prime}$ is not serially correlated; the remaining variables have the same interpretation as those in the equations (5) and (6). The $H_{0}$ to be tested reads (after the transformation) $H_{0}: \psi_{1}=\psi_{2}=0$. Both models can be estimated for all three possibilities alike the previous ESTAR model. As the model is a nonlinear, simulated critical value for the test statistics (a F-test) area tabled in Sollis (2009).

Since ESTAR and AESTAR models are nested, in the case of rejecting the $H_{0}$ against the $H_{A}$ (stationary symmetric or asymmetric ESTAR nonlinearity), it can be tested the null of symmetric against the alternative of asymmetric ESTAR nonlinearity in the model (9). A standard F-test can be used with the $H_{0}: \psi_{2}=0$ against $H_{1}: \psi_{2} \neq 0 .{ }^{12}$ However, critical values for the F-test are asymptotically valid only in the case of $\psi_{1}<0$, (i.e. stationary time series under the null hypothesis).

\subsection{Which test to use - linear model vs. nonlinear models}

Having described linear and nonlinear URTs, it is necessary to decide whether it is possible to rely on results of some type of tests. Since exponential models are utilized in this paper, Teräsvirta (1994) suggests a test for testing linearity against ESTAR or LSTAR alternatives: $H_{0}: \alpha_{1 i}=\alpha_{2 i}=\alpha_{3 i}, i=1, \ldots, r$ and the alternative $H_{A}:$ non $H_{0}$ :

12 If the $\xi_{2}$ in the model (7), the models (8), (9) collapse to the models (5) and (6), respectively. 


$$
x_{t}=\alpha_{00}+\sum_{i=1}^{r} \alpha_{0 i} x_{t-i}+\sum_{i=1}^{r} \alpha_{1 i} x_{t-i} x_{t-d}+\sum_{i=1}^{r} \alpha_{2 i} x_{t-i} x_{t-d}^{2}+\sum_{i=1}^{r} \alpha_{3 i} x_{t-i} x_{t-d}^{3}+\varepsilon_{t}
$$

As mentioned in the previous parts, in the ESTAR model, the parameter $\xi$ drives the speed of adjustment. If the transition is equal to zero, the adjustment process is linear. The decision whether to use a linear or nonlinear model can be based on a test that works with the null $H_{0}: \zeta=0$ and the alternative $H_{A}: \zeta>0$. For this test, an F-test is used (instead of a LM test) that should lead to higher power of the test - for lag lengths and small number of observations, the power of the LM test is low (Giannellis and Papadopoulos, 2009). Therefore, Teräsvirta (1994) suggests not using the LM test in any of those cases. The test procedure has several steps: firstly, the lag length $(p)$ must be appropriate for the time series being tested for linearity to obtain unbiased results. In all empirical estimations shown in the text, the number of lags suggested by the (SBIC) criterion is used. Secondly, the null hypothesis has to be tested for various delay parameters $(d)$. According to Tsay (1989), $d$ is chosen such that the p-value of the linearity test reaches its lowest value. In our case the parameter $d \in\langle 1,4\rangle$ and the appropriate value is the one for which p-value of the F-test is minimised.

\subsection{Structural breaks}

Since there may be a problem with a structural break and its impact on the power of $U R T S$, additional tests dealing with structural breaks are employed in this paper as well. The presence of a structural break can lead to the bias of conventional URTS against rejecting the $H_{0}$. It also changes implications from accepting/rejecting the null hypothesis of non-stationarity, i.e. for the PPP hypothesis. If a test allowing for structural breaks does not reject that a time series is stationary, deviations associated with a shock affecting this time series are considered temporary, i.e. PPP does hold in the long run. However, if there is a shock having impact on a time series that leads to changes in its mean or its time trend, PPP does not hold even in the long run.

Therefore, there have been suggested several alternative concepts of PPP compatible with the existence of breaks in time series in the literature. Dornbusch and Vogelsang (1991) propose 'quasi PPP' ( $q P P P)$ when a real exchange rate is stationary around a mean that may change. Hegewood and Papell (1998) work with this idea and extend the $q P P P$ concept to multiple endogenous breaks (one or two in intercept). Recently, Papell and Prodan (2006) distinguish between 'trend PPP' ( $t P P P$ ) and 'trend qualified PPP' (tqPPP). A real exchange rate including a time trend that is shown to be stationary is understood as $t P P P$; if there are one or two changes in the intercept, but a time series is stationary, it is $t q P P P$. A time series with structural breaks ( $t P P P$ or $t q P P P$ 'type') means a necessary condition for PPP, but PPP hypothesis holds only if there is a reversion towards a mean or a constant time trend (Yavuz, 2009). 


\section{Linear tests allowing for possible structural breaks}

To start with, linear URTs allowing for structural breaks were suggested by Perron (1997) ('first generation'). Perron (1997) allows for a structural break either in an intercept, a trend or in both. Break points are determined from the data set (endogenously). The existence of structural breaks is allowed only under the alternative hypothesis $\left(H_{A}\right)$ and not under the null $\left(H_{0}\right)$, i.e. it is a non-stationary time series with a structural break. ${ }^{13}$ More recent URTS are represented by Lee and Strazicich $(2003,2004)$ ('second generation') that deal with limitations of a Perron's type test. These tests allow for one or two structural breaks that can be under either of the hypotheses and uses a minimum Lagrange Multiplier (LM) test (for details see both original articles). Apart from these tests, there have been suggested many nonlinear tests in the literature. One representative of this type of tests - Bierens test - is utilised in this study as well (see below).

\section{Non-linear approach - the Bieren's test}

This test (Bierens, 1997) helps to overcome problems with structural breaks as nonlinear trends are approximated by interrupted (broken) time trends. It assumes non-stationarity under the $H_{0}$, and nonlinear trend stationarity under the $H_{1}$. It extends the ADF regression with a Chebishev polynomial term $\left(\theta^{T} P_{t, n}^{(m)}\right)$. The process can be written as:

$$
\Delta x_{t}=\gamma x_{t-1}+\sum_{i=1}^{k} w_{i} \Delta x_{t-i}+\theta^{T} P_{t, n}^{(m)}+v_{t},
$$

where $\theta^{T} P_{t, n}^{(m)}=\left(P_{0, n(t)}^{\prime}, \ldots, P_{m, n(t)}^{\prime}\right)$ are the Chebishev polynomials and $m$ is the order of the polynomials. Under the $H_{0}: \gamma=0$ and the last $m$ components of $\theta$ are zero.

There are three possibilities that can be tested (Bierens, 1997): ${ }^{14}$

1. all coefficients $(\gamma, \hat{t}(m))$ are tested via t-test;

2. $\hat{A}(m)$ test, $\hat{A}(m)=\frac{n \hat{\gamma}}{\left|1-\sum_{j=1}^{r} \hat{\omega}_{i}\right|}$ or;

3. the joint hypothesis $(\hat{F}(m))$ that under the $H_{0}: \hat{\gamma}=0$ and the last $m$ components of $\theta$ are zero.

As Cuestas (2009) mentions, rejection of the left side hypothesis for the first and second tests means linear or nonlinear trend stationarity. (It cannot be decided which of the cases is true.) Rejection of the right side means nonlinear trend stationarity. The third test is a one-sided test that does not give us any answer regarding the trend as right side rejection is only the rejection of the $H_{0}$. All possibilities are summarised in the Table 1 .

13 However, some recent studies have employed them; see e.g. Giannellis and Papadopoulos (2009).

14 As the tests Nos. 1 and 2 do not accommodate all information available, the test No. 3 is added. 
Table 1

Alternative Hypotheses for the Bierens Test

\begin{tabular}{|l|c|c|}
\hline Test & Left-side rejection & Right-side rejection \\
\hline$\hat{t}(m)$ & ST, TST or NTST & NTST \\
\hline$\hat{A}(m)$ & ST, TST or NTST & NTST \\
\hline$\hat{F}(m)$ & - & ST, TST or NTST \\
\hline
\end{tabular}

Note: ST - (mean) stationary, TST - (linear) trend stationary, NTST - nonlinear (trend) stationarity. The $F(m)$ test is only a one-sided test, the $t(m)$ and the $A(m)$ are specified for both sides. Source: Cuestas (2009), p. 92, own adaptation.

\section{Data}

Empirical studies have used different sorts of data as there is no prior information. While some have worked with monthly data for example Telatar and Hasanov (2009), others used quarterly or even yearly data Solakoglu (2006). Due to the problems with data availability for the early 1990s, methodological changes in definitions of economic variables and a set of issues associated with exchange rate regimes in the CEE countries, this study relies on quarterly data starting in 1995. This decision is also connected with some advantages and disadvantages. The time span is longer for quarterly data than it would have been for monthly data and it is a reasonable way of solving the problem of low number of yearly observations.

Nominal exchange rates for individual pairs of currencies (against the euro) are obtained primarily from the UNECE Statistical Database (market rates against the euro), Database Eurostat and DataStream. The calculation of cross exchange rates was avoided as there may be significant differences due to failure of perfect triangular arbitrage. Also official exchange rates are not used as they may not reflect market forces (for a discussion of some related issues see e.g. Giannellis and Papadopoulos (2009). Since the euro exchange rate is not available before 1999Q1 (only the ECU), an implicit proxy derived from bilateral exchange rates (UNECE) is used instead. ${ }^{15}$

Harmonised consumer price indices (HICP) are taken from the Eurostat with the base year $2005=100$. The same data for the euro area stem from the Eurostat database and the ECB statistical data warehouse. For seasonal adjustments, the ARIMA X-12 method is applied. Selected summary statistics for our time series are in the Appendix.

\section{Empirical Analysis - Euro Currency Pairs}

Euro currency pairs for individual countries are employed to test the PPP hypothesis via $U R T s$. The main specification rests upon real exchange rates (RER), based on harmonized consumer price indices (HICP). The first step is to conduct conventional

15 As there have been denominations and changes of individual currencies, our data set includes comparable time series. Due to space constraints details from the author are available upon request. 
URTs for our sample of countries. A starting point is to choose 'right' lag lengths for $U R T s$, so that results are unbiased. This selection follows the Schwert (1989) criterion (ADF, PP, KPSS and DF-GLS ${ }^{16}$ ) and is confirmed by checking values suggested by the Schwartz (Bayesian) information criterion (SBIC). As we are not sure about the character of individual time series (the true data generating process), models with a constant, drift or a constant and a time trend are employed. The results are presented in the Table 2 .

To begin with, the ADF test offers a mixed picture, as most of the time series seem to be non-stationary (only Lithuanian and Macedonian currencies are stationary in both versions of the test). The PP test indicates that three exchange rates may be stationary (Bulgarian, Croatian, Estonian, Lithuanian and Turkish) - while for Lithuania it does confirm the ADF results, it is the very opposite for Estonia. The results of the KPSS test (the $H_{0}$ is stationarity) indicate that almost all time series are non-stationary. Ambiguous results for Croatian, Cyprian, Slovenian and Turkish currency indicate rejections of the PPP hypothesis in the long run. The results of the DF-GLS test does not allow us to reject the null hypothesis of I(1) in any specification except from the Croatian, Macedonian, Slovenian and Turkish exchange rate (each only in one specification). ${ }^{17}$ Since the results for the alternative price index (PPI) are similar, they are not shown. ${ }^{18}$

Table 2

\section{Univariate Unit Root Tests}

\begin{tabular}{|c|c|c|c|c|c|c|c|c|}
\hline & \multicolumn{2}{|c|}{$A D F^{a)}$} & \multicolumn{2}{|c|}{ PPa) } & \multicolumn{2}{|c|}{ KPSS $^{\text {b) }}$} & \multicolumn{2}{|c|}{ DF-GLS } \\
\hline & constant & trend & constant & trend & constant & trend & constant & trend \\
\hline Bulgaria & -0.633 & -1.441 & $-2.751^{*}$ & $-6.362^{* * *}$ & $1.530^{\star * *}$ & $0.198 \mathrm{c})$ & 1.028 & -0.511 \\
\hline Croatia & -0.922 & $-3.553^{\star *}$ & -1.227 & $-3.183^{*}$ & $1.580^{\star \star *}$ & 0.117 & 0.522 & $-3.855^{\star \star \star}$ \\
\hline Czech Rep. & -0.801 & $-3.425^{\star *}$ & -0.854 & $-3.250^{\star * *}$ & $1.430^{\star \star *}$ & $0.293^{* * *}$ & 0.072 & -1.385 \\
\hline Hungary & -1.482 & -2.212 & -0.880 & -2.846 & $1.630^{\star * *}$ & $0.237^{\star \star \star}$ & 0.236 & -0.8221 \\
\hline Lithuania & $-5.316^{\star \star \star}$ & $-4.557^{\star \star \star}$ & $-5.462^{* * \star}$ & $-3.824^{\star \star}$ & $1.320^{* * *}$ & $0.307^{* * *}$ & 1.155 & -1.519 \\
\hline Latvia & -2.186 & -2.477 & $-2.915^{\star *}$ & -2.446 & $1.140^{\star \star *}$ & $0.198 \mathrm{c})$ & 0.685 & -1.789 \\
\hline Macedonia & $-4.609^{* * *}$ & $-4.393^{* * *}$ & -2.189 & -1.709 & $0.487^{* *}$ & $0.255^{\star \star *}$ & -1.373 & $-3.532^{* *}$ \\
\hline Poland & -2.174 & -2.705 & -2.287 & -2.654 & $1.070^{* * \star}$ & $0.143^{*}$ & -0.651 & -2.333 \\
\hline Romania & -1.528 & -2.344 & -1.432 & -2.425 & $1.380^{\star \star *}$ & $0.147^{\star *}$ & -0.145 & -2.186 \\
\hline Turkey & -1.700 & $-4.410^{* * *}$ & -1.702 & $-3.994^{\star * \star}$ & $1.540^{* * *}$ & 0.084 & 0.351 & $-4.138^{* * *}$ \\
\hline
\end{tabular}

Note: a) $Z(t)$ values reported. $\left.{ }^{b}\right)$ values of the test statistics. ${ }^{c}$ significant at $2.5 \%$ level. ***, ${ }^{* *}$, and * significant at $1 \%$, $5 \%$ and $10 \%$ respectively. Critical values for the KPSS test (level stationary): $10 \%: 0.347,5 \%: 0.463,2.5 \%: 0.574$ and 1\%: 0.739 ; trend stationary: $10 \%: 0.119,5 \% 0.146,2.5 \%: 0.176$, and $1 \%: 0.216$. Trend $=$ a constants and a time trend included. Source: own calculation.

In the next step, we turn to robust and nonlinear URTS that may solve problems of breaks within time series for example due to changes of exchange rate regimes over

16 Optimal lag values were based on the Ng-Perron seq $t$-statistics (the general to specific method).

17 The DF-GLS statistics is superior to the ADF statistics as its power (lower probability of accepting wrong null hypothesis of non-stationarity) and size properties are better Wu et al. (2010).

18 Results are available upon request from the author. 
time. First test is the Perron test, followed by nonlinear test, the KSS test (ESTAR), and the Sollis test (AESTAR). The Perron test rejects the $H_{0}$ for two currency pairs (Croatian and Turkish), and for four more only marginally does not.

In the previous (methodological) part of this paper we showed a test that gives us answer what type of URTS test is appropriate. Results of this linearity test (see Appendix) that conventional $U R T S$ are appropriate to test stationarity or non-stationarity of exchange rates in the Czech Republic, Hungary, Lithuania, Latvia, and Slovenia. Therefore, we do report results of ESTAR and AESTAR model for these countries in the Table 3 in parentheses since according to the test, they are not necessary.

Table 3

Nonlinear Univariate Unit Root Tests Results (euro currency pairs, HICP based indices)

\begin{tabular}{|l|c|c|c|c|}
\hline \multirow{2}{*}{ Bulgaria } & \multicolumn{2}{|c|}{ Perron } & \multirow{2}{*}{ ESTAR } & \multirow{2}{*}{ AESTAR } \\
\cline { 2 - 3 } & break date & statistics & & $18.86^{* * *}$ \\
\hline Croatia & $2002: 2$ & -3.618 & -2.27 & 1.18 \\
\hline Czech Republic & $2004: 4$ & $-4.339^{\text {a) }}$ & -1.54 & -0.01 \\
\hline Hungary & $1995: 2$ & $-4.415^{\text {a) }}$ & $(-1.60)$ & -3.45 \\
\hline Lithuania & $2004: 3$ & -2.345 & $(-1.80)$ & $\left(7.77^{* * *}\right)$ \\
\hline Latvia & $1997: 4$ & -3.649 & $\left(-3.01^{* *}\right)$ & -0.2 \\
\hline Macedonia & $1996: 3$ & -3.436 & $(-1.73)$ & $5.29^{*}$ \\
\hline Poland & $1996: 2$ & $-4.413^{\text {a) }}$ & -1.41 & 4.95 \\
\hline Romania & $19000: 3$ & -3.339 & $-2.87^{*}$ & 0.03 \\
\hline Turkey & $2002: 1$ & -3.493 & -2.29 & 0.13 \\
\hline
\end{tabular}

Note: Perron 1997 test - AO test, ESTAR \& AESTAR models are in the demeaned version, the optimal number of lags selected by the general to specific method. Critical values for all tests are in the Table 4. a) marginally insignificant. Values in parentheses - see explanations in the text. Source: own calculation.

If we now allow for the possibility of a non-linear model, there is some evidence against the null for one currency pair (Polish). The figure is therefore slightly different compared to previous results based on conventional URTs. It gives much more support to PPP and it is similar to findings of other studies, e.g. Telatar and Hasanov (2009). It also implies that barriers to adjustment processes exist. For example, transaction costs change the speed of mean reversion (larger deviations will be followed by faster gap narrowing).

If exchange rates are found to be stationary, it is possible to test whether adjustments are symmetrical or asymmetrical. As we reject the null of nonlinearity for Bulgarian and Macedonian currency using the AESTAR test, it is possible to test the existence of asymmetrical adjustments. This can be done by testing $H_{0}: \psi_{2}=0$ in the model (11) or (12). The null hypothesis of a symmetric ESTAR for both countries can be rejected (at $5 \%$ level). This means that a shock of the same magnitude affecting this exchange rate leads to different adjustments speeds towards equilibrium for an appreciation and for a depreciation. 
Table 4

Critical Values for Perron, ESTAR and AESTAR Tests

\begin{tabular}{|c|c|c|c|}
\hline & Perron test & ESTAR & AESTAR \\
\hline $\mathbf{1} \%$ & -5.45 & -3.48 & 4.037 \\
\hline $\mathbf{5 \%}$ & -4.83 & -2.93 & 4.899 \\
\hline $\mathbf{1 0} \%$ & -4.48 & -2.66 & 6.889 \\
\hline
\end{tabular}

Note: The critical values for Perron test taken from Perron (1997), p. 362, the critical values for ESTAR are taken from Kapetanios et al. (2003), Table 1, F-test (AESTAR model), values for non-zero mean (simulated values) based on Sollis (2009).

Finally, we allow for the possibility of structural breaks in currency pairs; one and two both in the mean and in the trend. Results of Lee and Strazicich $(2003,2004)$ are in the Table 5. Given the fact that the NMS countries are catching-up economies, undergoing structural changes and more recently they have been hit by the financial crisis, structural breaks may have occurred. Omitting them leads to problems in the case of conventional URTS as shown above. If we allow for one structural break (the left side of the table), the null of non-stationarity can be rejected in four cases (Croatia, Hungary, Macedonia and Turkey). Surprisingly, there is no break around the outbreak of the financial crisis $(2007 / 2008)$ for all but one currency.

Table 5

\section{Lee and Strazicich Test}

\begin{tabular}{|l|c|l|c|c|c|}
\hline & TB1 & Statistics & TB1 & TB2 & Statistics \\
\hline Bulgaria & $1999: 3$ & $-2,2364$ & $2000: 3$ & $2006: 4$ & $-3,5129$ \\
\hline Croatia & $2007: 1$ & $-4.6332^{* *}$ & $2004: 2$ & $2008: 4$ & $-5.1972^{*}$ \\
\hline Czech Republic & $2000: 3$ & $-3,9800$ & $2003: 1$ & $2007: 2$ & $-5.3399^{\star *}$ \\
\hline Hungary & $2001: 3$ & $-4.5807^{* *}$ & $2000: 4$ & $2005: 2$ & $-5.4938^{\star *}$ \\
\hline Lithuania & $2000: 3$ & $-3,4395$ & $2000: 3$ & $2007: 2$ & $-5.9600^{\star * *}$ \\
\hline Latvia & $2001: 4$ & $-3,2736$ & $2001: 4$ & $2006: 4$ & $-5.1996^{*}$ \\
\hline Macedonia & $2003: 1$ & $-6.3618^{\star * *}$ & $2003: 1$ & $2007: 1$ & $-7.1895^{\star * *}$ \\
\hline Poland & $2002: 4$ & $-3,7584$ & $2002: 3$ & $2006: 2$ & $-4,6207$ \\
\hline Romania & $1998: 4$ & $-3,8248$ & $2002: 4$ & $2007: 2$ & $-5.5972^{\star * *}$ \\
\hline Turkey & $2003: 4$ & $-4.8015^{* *}$ & $2002: 4$ & $2005: 4$ & $-6.0485^{\star * *}$ \\
\hline
\end{tabular}

Note: TB1 and TB2 - the time period when the first and the second structural break, respectively. The model assumes a change in the drift and in the trend. Critical values are based on Lee and Strazicich (2004), Table 1, Lee and Strazicich (2003), Table 2: TB1 test: 1\%: -5.10, 5\%: -4.50 , and 10\%: -4.20 . TB1 and TB2 test: $1 \%:-5.823,5 \%-5.286$, and 10\%: $-4.989 .{ }^{*},{ }^{* *}$ and ${ }^{* * *}$ means rejection at $10 \%, 5 \%$, and $1 \%$ level of significance, respectively. Source: own calculation

However, allowing for the possibility of two structural breaks (the right side of the table - its columns 4-6), the null of non-stationarity is rejected in eleven out of fifteen cases. It can be seen that first breaks are within the year 2000 (five) and years 2001 and 2002 apart from three countries, which may be explained by changes in the global economy or as a result of the EU enlargement. Also the other breaks do not seem to be related to the on-going financial crisis and problems of major financial institutions since five breaks are found in 2006, six in 2007 (mostly first half) and only one in 2008 (Croatia). 
Table 6

Univariate Unit Root Test - the Bierens (1997) Test (euro currency pairs)

\begin{tabular}{|c|c|c|c|c|c|c|c|}
\hline & Test & t. statistics & P-value & & Test & t. statistics & P-value \\
\hline \multirow{3}{*}{ Bulgaria } & $\hat{t}(m)$ & -3.642 & {$[0.0872]$} & \multirow{3}{*}{ Latvia } & $\hat{t}(m)$ & -2.408 & {$[0.5067]$} \\
\hline & $\hat{A}(m)$ & -35.463 & {$[0.0690]$} & & $\hat{A}(m)$ & -16.005 & {$[0.3798]$} \\
\hline & $\hat{F}(m)$ & 4.540 & {$[0.8676]$} & & $\hat{F}(m)$ & 2.641 & [0.4125] \\
\hline \multirow{3}{*}{ Croatia } & $\hat{t}(m)$ & -2.447 & {$[0.4917]$} & \multirow{3}{*}{ Macedonia } & $\hat{t}(m)$ & 2.266 & {$[0.5687]$} \\
\hline & $\hat{A}(m)$ & -15.756 & {$[0.4027]$} & & $\hat{A}(m)$ & -6.847 & {$[0.7510]$} \\
\hline & $\hat{F}(m)$ & 2.486 & [0.4321] & & $\hat{F}(m)$ & 3.055 & [0.5811] \\
\hline \multirow{3}{*}{ Czech Republic } & $\hat{t}(m)$ & -3.683 & {$[0.0872]$} & \multirow{3}{*}{ Poland } & $\hat{t}(m)$ & -3.061 & {$[0.2624]$} \\
\hline & $\hat{A}(m)$ & -39.62 & {$[0.0512]$} & & $\hat{A}(m)$ & -18.362 & [0.2443] \\
\hline & $\hat{F}(m)$ & 4.591 & {$[0.8587]$} & & $\hat{F}(m)$ & 3.249 & {$[0.6196]$} \\
\hline \multirow{3}{*}{ Hungary } & $\hat{t}(m)$ & -2.127 & {$[0.6221]$} & \multirow{3}{*}{ Romania } & $\hat{t}(m)$ & -2.321 & {$[0.5600]$} \\
\hline & $\hat{A}(m)$ & -14.211 & {$[0.4547]$} & & $\hat{A}(m)$ & -10.726 & [0.5125] \\
\hline & $\hat{F}(m)$ & 1.769 & [0.2132] & & $\hat{F}(m)$ & 1.972 & [0.2690] \\
\hline \multirow{3}{*}{ Lithuania } & $\hat{t}(m)$ & -3.674 & {$[0.1017]^{a)}$} & \multirow{3}{*}{ Turkey } & $\hat{t}(m)$ & -4.652 & {$[0.0117]$} \\
\hline & $\hat{A}(m)$ & -10.360 & [0.5680] & & $\hat{A}(m)$ & -46.553 & {$[0.0065]$} \\
\hline & $\hat{F}(m)$ & 6.898 & {$[0.9714]$} & & $\hat{F}(m)$ & 7.223 & [0.9799] \\
\hline
\end{tabular}

Note: p-values in brackets. Rejection of the $H_{0}$ is in bold. a) Marginally rejected. Source: own calculations.

The results of the last non-linear URTs, the Bierens (1997) test, are shown in the Table 6. As there are several size distortions in the case of this test, the critical values are based on the Monte Carlo simulation with 10,000 replications (a Gaussian $A R(k)$ process for $\Delta x_{t}$, where $k$ is determined by the SBIC criterion and initial values are taken from particular time series.) If individual tests are not concordant, more lags are included in the model. The order for the Chebishev polynomials $(m)$ must be chosen long enough, as a lack of lags compared to structural breaks might result in lower power of the test. However, there is no simple rule for its determination. In our case, we follow the suggestion of Cuestas (2009), i.e. the lag length is chosen so that it yields more evidence against the null $\left(H_{0}\right)$.

Our results show a rejection of the left-sided hypothesis for the Bulgarian, Czech and Turkish currency pairs, however, do not allow us to conclude whether they are (mean) stationary, stationary with a linear trend or a stationary around a nonlinear trend (recall the Table 1). There is only one significant result for the Lithuanian currency pair, some other ones are (marginally) insignificant. (Following recommendations in Bierens (1997) as regards cases when only one out of three test statistics indicates that PPP holds.) Interestingly, the results for Bulgarian or Hungarian currency are found highly significant in Cuestas (2009), ${ }^{19}$ but results for other countries are similar.

19 It may have been due to the inclusion of the time period covering the early 1990 s. 


\section{Is the 'PPP Puzzle' Still Present?}

As we have seen, the results are rather ambiguous and do not provide clear guidance regarding the PPP hypothesis for the group of European transition countries. What maybe the possible reasons for these findings? Possible problems and/or reasons for the lack of clear-cut evidence in the analysis of the PPP can be divided into three groups (for details Žd'árek, 2010).

The first group includes problems and issues related to available data. Some of them can be labelled as problems of transition countries. Since our time span starts in the mid 1990s, it gives us enough observations in the time dimension, but may also be the reason why results are rather mixed (e.g. due to the changes in exchange rate arrangements). In a similar vein, the measures of inflation may have been exposed to similar kind of shocks. Therefore, the problem may be due to the utilised price indices and not due to the exchange rates. However, there may be large discrepancies between official exchange rates and cross exchange rates calculated under the assumption of perfect triangular arbitrage. If the former is less volatile, it means possible central banks' interventions in the foreign exchange markets.

The second group encompasses various measures applied in an economy. One of them can be in the form of exchange rate arrangements, such as the ERM II. This may have restricted the exchange rates of CEE countries and therefore, the results of URTS. The euro as a benchmark for our analysis may also influence our results, as it was an artificial currency in the 1990s. However, this choice seems to be rational, since the US dollar seems to have lost much of its importance in the CEE countries and the euro/ ECU has gained significance due to European integration process. In addition, some authors argue that the RER are not I(1) but rather I(0) process that has a non-linear trend or with structural breaks. This may give support to the notion of a 'quasi-PPP' or 'a relaxed version of PPP' (see e.g. Cuestas and Regis, 2008).

Finally, the last group incorporates empirical problems and problems of econometric methods that can be utilised. One of them may be a group of issues related to the problem called fractional integration of time series.

Even though it is not possible to list and discuss all possible problems and issues related to the tests of the PPP hypothesis, given the space limitations of this paper, the aforementioned ones can help us to answer the question stated in the title of this subsection. The 'PPP puzzle' is still alive at least in the transition (and developing) countries and it is not obvious when we will have such (empirical) tools that will give us a clear answer.

\section{Conclusions}

This paper focused on testing the relative version of the PPP in the European transition countries over the time span of 16 years. It tried to shed some light on the 'old PPP puzzle' for a group of countries that do not use the euro. It was argued that the PPP concept 
plays a very important role in various fields - both theoretical concepts (exchange rate modelling) and policy-making including impacts of various actions and measures.

Firstly, the results for conventional (linear) URTs provide mild evidence in favour of the PPP hypothesis. Secondly, for countries where cannot be decided using linear tests, more robust versions of URTs and non-linear URTs (ESTAR and AESTAR models or the Bierens test) are applied, show mixed results and are in line with the literature. Finally, our results for non-linear test allowing for structural breaks (Lee and Strazicich, 2003, 2004) tend to provide evidence for the existence of PPP. Interestingly, dates of individual structural breaks are not necessarily linked to the outbreak of the on-going financial crisis, but they seem to reflect changes in the global economy or some important events (e.g. phases of the EU integration process).

Apart from many 'technical reasons' (econometric techniques and methodologies), one of the key explanations for our ambiguous results can be the length of time period used in this study. While exchange rates data are mostly available, problems arise with economic variables for testing the PPP hypothesis. Likewise, the quality of the data from the early 1990s seems to be rather questionable. In addition, most of the European transition countries used in this study were subject to non-economic influences (interventions), which may invalidate any economic approach trying to capture underlying economic determinants and processes. Nevertheless, the findings can be used as a piece of information when working with exchange rates models and policy-makers when making decisions based on the results of models assuming PPP holds.

\section{Appendix}

Table A1

Teräsvirta's Linearity Test

\begin{tabular}{|l|c|c|c|c|c|}
\hline Exchange rate & $p$ & $d$ & F-statistics & Probability & Conclusion \\
\hline Bulgaria & 9 & 1 & 30.776 & 0.0000 & NL model \\
\hline Croatia & 1 & 1 & 1.2134 & 0.3128 & L model \\
\hline Czech Republic & 3 & 2 & 1.629 & 0.1332 & L model \\
\hline Hungary & 3 & 2 & 1.729 & 0.1075 & L model \\
\hline Lithuania & 1 & 1 & 1.395 & 0.2533 & L model \\
\hline Latvia & 2 & 2 & 0.471 & 0.8286 & L model \\
\hline Macedonia & 6 & 1 & 17.4629 & 0.0000 & NL model \\
\hline Poland & 2 & 2 & 3.726 & 0.0036 & NL model \\
\hline Romania & 2 & 4 & 4.492 & 0.0010 & NL model \\
\hline Turkey & 1 & 1 & 1.7876 & 0.1594 & L model \\
\hline
\end{tabular}

Note: $\mathrm{p}$ - the number of lags, $\mathrm{d}$ - the value of the delay parameter. $\mathrm{NL}-$ non-linear model, $\mathrm{L}-$ linear model. Source: own calculation. 
Table A2

Summary Statistics

\begin{tabular}{|l|c|c|c|c|}
\hline & & ER $^{\text {a) }}$ & hicp & () \\
\hline Bulgaria & mean & 1.071 & 4.091 & 0.7813 \\
& SD & 0.617 & 1.208 & 0.2852 \\
\hline Croatia & mean & 7.310 & 4.541 & 2.0177 \\
& SD & 0.245 & 2.688 & 0.0546 \\
\hline Estonia & mean & 31.969 & 4.533 & 3.4581 \\
& SD & 3.787 & 0.160 & 0.1801 \\
\hline Hungary & mean & 15.588 & 4.507 & 2.7862 \\
& SD & 0.197 & 0.226 & 0.1349 \\
\hline Lithuania & mean & 241.575 & 4.399 & 5.6332 \\
& SD & 29.819 & 0.347 & 0.1587 \\
\hline Latvia & mean & 3.900 & 4.584 & 1.3055 \\
& SD & 0.632 & 0.151 & 0.2194 \\
\hline Macedonia & mean & 0.656 & 4.523 & -0.397 \\
& SD & 0.052 & 0.237 & 0.1509 \\
\hline Poland & mean & 59.409 & 4.586 & 4.0598 \\
& SD & 4.051 & 2.433 & 0.0696 \\
\hline Romania & mean & 3.897 & 4.463 & 1.4424 \\
& SD & 0.388 & 0.241 & 0.1254 \\
\hline Turkey & mean & 2.535 & 3.816 & 1.4328 \\
& SD & 1.366 & 1.141 & 0.2216 \\
\hline
\end{tabular}

Note: SD - standard deviation, a) absolute values, ${ }^{\text {b) }}$ natural logs of seasonally adjusted indices, c) natural logs of original values.

Figure A1

Exchange Rates of the CEE Countries
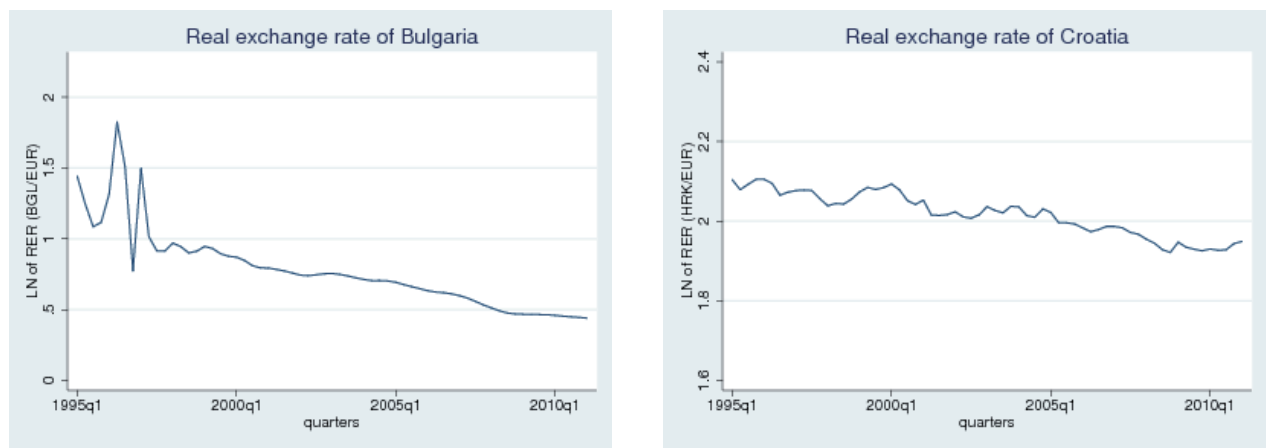
Figure A1 - continuation
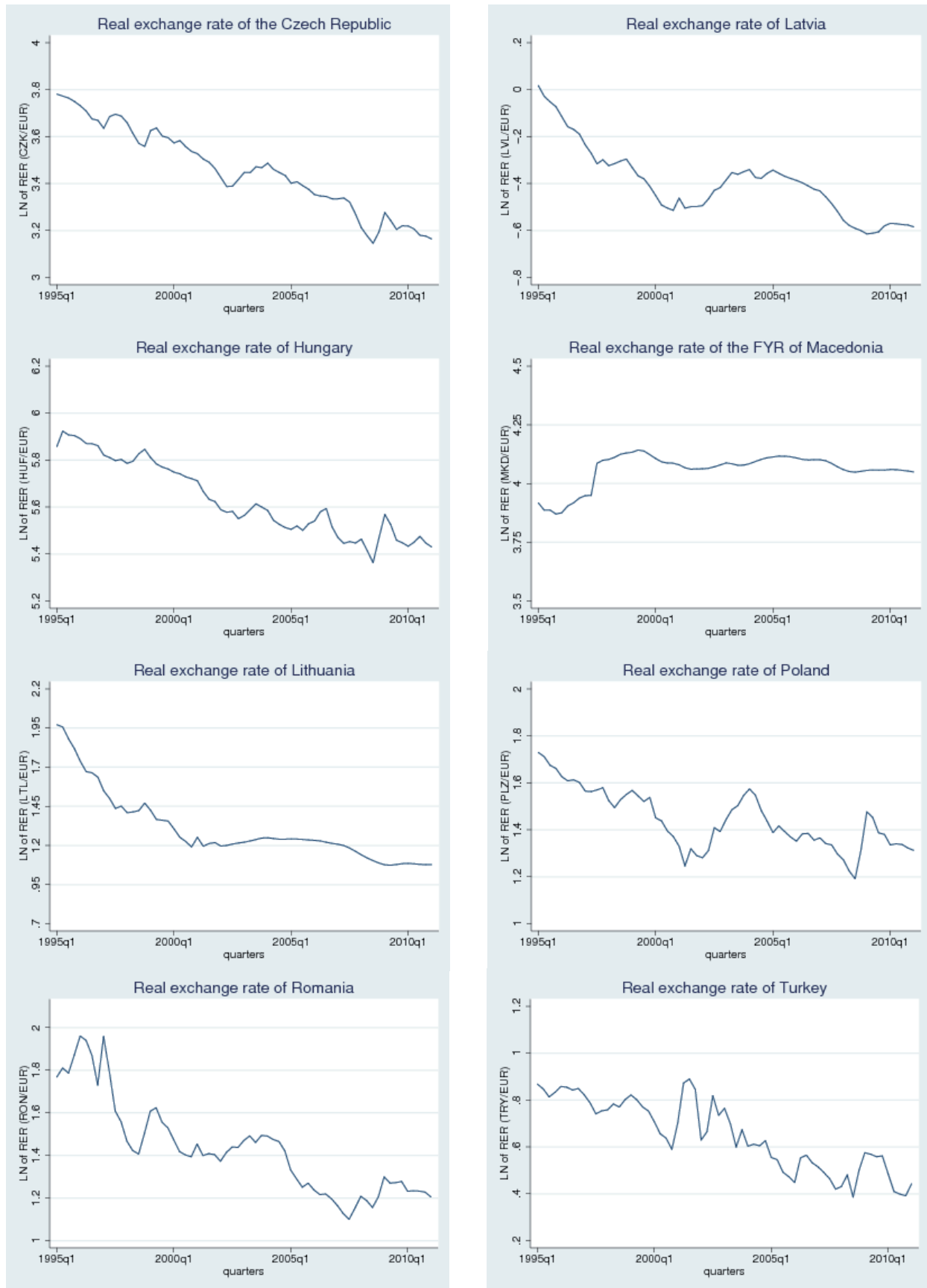

Notes: various scales on vertical axes.

Source: see text. 


\section{References}

Acaravci, A., Ozturk, I. (2010), "Testing Purchasing Power Parity in Transition Countries: Evidence from Structural Breaks." Economic Interferences, Vol. XII, No. 27, p. 190-198.

Alba, J. D., Papell, D. H. (2007), "Purchasing Power Parity and Country Characteristics: Evidence from Panel Data Tests." Journal of Development Economics, Vol. 83, Issue 1, pp. 240-251.

Bahmani-Oskooee, M., Kutan, A. M., Zhou, S. (2008), "Do Real Exchange Rates Follow a Nonlinear Mean Revering Process in Developing Countries?" Southern Economic Journal, Vol. 74, No. 4, pp. 1049-1062.

Bekö, J., Boršiè, D. (2007), "Purchasing Power Parity in Transition Economies: Does it Hold in the Czech Republic, Hungary and Slovenia?" Post-Communist Economies, Vol. 19, No. 4, pp. 417-432.

Bierens, H. J. (1997), "Testing the Unit Root Hypothesis Against Nonlinear Trend Stationarity, With an Application to the Price Level and Interest Rate in the U.S." Journal of Econometrics, Vol. 81, Issue 1, pp. 29-64.

Chortareas, G., Kapetanios, G. (2009), "Getting PPP Right: Identifying Mean-reverting Real Exchange Rates in Panels." Journal of Banking \& Finance, Vol. 33, Issue 2, pp. 390-404.

Christidou, M., Panagiotidis, T. (2010), "Purchasing Power Parity and the European Single Currency: Some New Evidence." Economic Modelling, Vol. 27, Issue 5, pp. 1116-1123.

Cuestas, J. C. (2009), "Purchasing Power Parity in Central and Eastern European Countries: an Analysis of Unit Roots and Nonlinearities." Applied Economic Letters, Vol. 16, No. 1, pp. 87-94.

Cuestas, J. C., Regis, P. J. (2008), "Testing PPP in Australia: Evidence from Unit Root Test against Nonlinear Trend Stationary Alternatives." Economics Bulletin, Vol. 3, No. 27, pp. 1-9.

ECB (2011), Statistical Data Warehouse. ECB, Frankfurt, 2011.

Eurostat (2011), Database (on-line). Luxembourg, 2011. URL: Eurostat.

Fan, J., Yao, Q. (2003), Nonlinear Time Series. Nonparametric and Parametric Methods. New York: Springer Verlag, 2003.

Giannellis, N., Papadopoulos, A. P. (2009), "Testing for Efficiency in Selected Developing Foreign Exchange Markets: An Equilibrium-based Approach." Economic Modelling, Vol. 26, No. 1, pp. 155-166.

Harris, R., Sollis, R. (2005), Applied Time Series. Modelling and Forecasting. Chichester: John Willey \& Sons, 2003, reprinted 2005.

Hegewood, N. D., Papell, D. H. (1998), "Quasi Purchasing Power Parity." International Journal of Finance and Economics, Vol. 3, No. 4, pp. 279-289.

IMF (2011), "International Finance Statistics" (on-line). IMF, Washington, D.C., July 2011.

Juvenal, L., Taylor, M. P. (2008), "Threshold Adjustment of Deviations from the Law of One Price." Studies in Nonlinear Dynamics \& Econometrics, Vol. 12, Issues 3, pp. 1-44.

Kapetanios, G., Shin, Y., Snell, A. (2003), "Testing for a Unit Root in the Nonlinear STAR Framework." Journal of Econometrics, Vol. 112, No. 2, pp. 359-379.

Koukouritakis, M. (2009), "Testing the Purchasing Power Parity: Evidence from the New EU Countries." Applied Economics Letters, Vol. 16, No. 1, pp. 39-44.

Lee, J., Strazicich, M. C. (2003), "Minimum Lagrange Multiplier Unit Root Test with Two Structural Breaks." The Review of Economics and Statistics, Vol. 85, No. 4, p. 1082-1089.

Lee, J., Strazicich, M. C. (2004), "Minimum LM Unit Root Test with One Structural Break." North Carolina, Appalachian State University, Department of Economics Working Papers No. 04-17, December 2004.

Macdonald, R. (2007), Exchange Rate Economics: Theories and Evidence. London \& New York: Routledge, 2007.

Maican, F. G., Sweeney, R. J. (2006), "Real Exchange Adjustment in European Transition Countries." Göteborg University, Department of Economics WP, No. 202, February 2006. 
Papell, D. H., Prodan, R. (2006), "Additional Evidence of Long-run Purchasing Power Parity with Restricted Structural Change." Journal of Money, Credit and Banking, Vol. 38, No. 5, pp. 1329-1349.

Perron, P. (1997), "Further Evidence on Breaking Trend Functions in Macroeconomic Variables." Journal of Econometrics, Vol. 80, No. 2, pp. 335-385.

Rogoff, K. (1996), "The Purchasing Power Parity Puzzle." Journal of Economic Literature, Vol. 34, No. 2, pp. 647-668.

Schwert, G. W. (1989), "Test for Unit Roots: A Monte Carlo Investigation." Journal of Business and Economic Statistics, Vol. 7, Issue 2, pp. 147-159.

Sideris, D. (2006), "Purchasing Power Parity in Transition: Evidence from Central and East European Countries." Applied Financial Economics, Vol. 16, No. 1\&2, pp. 135-143.

Solakoglu, E. G. (2006), "Testing Purchasing Power Parity Hypothesis for Transition Economies." Applied Financial Economics, Vol. 16, Issue 16, pp. 561-568.

Sollis, R. (2009), "A Simple Unit Root Test against Asymmetrical STAR Nonlinearity with an Application to Real Exchange Rates in Nordic Countries." Economic Modelling, Vol. 26, No. 1, pp. 118-125.

Taylor, M. P. (2005), "Is Official Exchange Rate Intervention Effective?" Economica, Vol. 71, Issue 281, pp. 1-11.

Taylor, A. M., Taylor, M. P. (2004), "The Purchasing Power Parity Debate.” Journal of Economic Perspectives, Vol. 18, No. 4, pp. 135-158.

Telatar, E., Hasanov, M. (2009), "Purchasing Power Parity in Central and East European Countries." Eastern European Economics, Vol. 47, No. 5, pp. 25-41.

Teräsvirta, T. (1994), "Specification, Estimation and Evaluation of Smooth Transition autoregressive Models." Journal of the American Statistical Association, Vol. 89, No. 425, pp. 208-218.

Thacker, N. (1995), "Does PPP Hold in the Transition Economies? The Case of Poland and Hungary." Applied Economics, Vol. 27, No. 6, pp. 477-481.

Tsay, R. S. (1989), "Testing and Modelling Threshold Autoregressive Processes." Journal of the American Statistical Association, Vol. 84, No. 405, pp. 231-240.

Yavuz, N. C. (2009), "Purchasing Power Parity with Multiple Structural Breaks: Evidence from Turkey." Economics Bulletin, Vol. 29, Issue 2, pp. 1201-1210.

Wu, J.-L., Cheng, S.-Y., Hou, H. (2010), "Further Evidence on Purchasing Power Parity and country Characteristics." International Review of Economics and Finance, Vol. 20, No. 2, pp. 257-266.

Žd'árek, V. (2010), "Some New Empirical Evidence on the Relative PPP Hypothesis in New EU Member States." Working Paper CES VŠEM, No. 10, December 2010. 